\title{
Speciation and dissolution of hydrogen in the proto-lunar disk
}

\author{
Kaveh Pahlevan ${ }^{1,2} *$, Shun-ichiro Karato ${ }^{2}$, Bruce Fegley ${ }^{3}$
}

1. Lagrange Laboratory, Observatoire de la Côte d'Azur, Nice, France.

2. Department of Geology and Geophysics, Yale University, New Haven, CT 06520 USA.

3. Planetary Chemistry Laboratory, Department of Earth and Planetary Sciences and The McDonnell Center for the Space Sciences, Washington University, St. Louis, MO 63130 USA.

*To whom correspondence should be addressed; Email: pahlevan@oca.eu

Submitted to EPSL May 11, 2015, Revised April 4, 2016 


\section{Abstract}

2 Despite very high temperatures accompanying lunar origin, indigenous water in the form of

$3 \mathrm{OH}$ has been unambiguously observed in Apollo samples in recent years. Such observations

4 have prompted questions about the abundance and distribution of lunar hydrogen. Here, we

5 investigate the related question of the origin of lunar $\mathrm{H}$ : is the hydrogen observed a remnant

6 of a much larger initial inventory that was inherited from a "wet" Earth but partly depleted

7 during the process of origin, or was primordial hydrogen quantitatively lost from the lunar

8 material, with water being delivered to lunar reservoirs via subsequent impacts after the

9 origins sequence? Motivated by recent results pointing to a limited extent of hydrogen

10 escape from the gravity field of the Earth during lunar origin, we apply a newly developed

11 thermodynamic model of liquid-vapor silicates to the proto-lunar disk to interrogate the

12 behavior of $\mathrm{H}$ as a trace element in the energetic aftermath of the giant impact. We find that:

13 (1) pre-existing H-bearing molecules are rapidly dissociated at the temperatures considered

$14(3,100-4,200 \mathrm{~K})$ and vaporized hydrogen predominantly exists as $\mathrm{OH}(\mathrm{v}), \mathrm{H}(\mathrm{v})$ and

$15 \mathrm{MgOH}(\mathrm{v})$ for nearly the full range of thermal states encountered in the proto-lunar disk, (2)

16 despite such a diversity in the vapor speciation - which reduces the water fugacity and

17 favors hydrogen exsolution from co-existing liquids - the equilibration of the vapor

18 atmosphere with the disk liquid results in significant dissolution of $\mathrm{H}$ into proto-lunar

19 magmas, and (3) equilibrium $\mathrm{H}$ isotopic fractionation in this setting is limited to $<10$ per mil

20 and the "terrestrial" character of lunar $\mathrm{D} / \mathrm{H}$ recently inferred should extend to such a

21 precision if liquid-vapor equilibration in the proto-lunar disk is the process that gave rise to

22 lunar hydrogen. Taken together, these results implicate dissolution as the process

23 responsible for establishing lunar $\mathrm{H}$ abundances. 
24 Keywords: Moon, origin, proto-lunar disk, water, hydrogen

\section{1. Introduction}

27 After decades of scientific thought maintaining that the Moon is essentially dry $(<1 \mathrm{ppb}$

$28 \mathrm{H}_{2} \mathrm{O}$ ), lunar samples have, in recent years, become recognized as carriers of measurable

29 indigenous water (Hauri et al., 2015). In this work, we use "indigenous" to refer to non-

30 solar-wind, non-cosmogenic sources such as inheritance from birth or implantation via

31 impactors (Bottke et al., 2010) and "water" to refer to various forms of hydrogen in silicate

32 glasses, minerals and melts (mostly as $\mathrm{OH}$ ) with concentrations representing the weight

33 percent of $\mathrm{H}_{2} \mathrm{O}$ that would be released upon degassing. In a pioneering study, (Saal et al.,

34 2008) measured tens of ppm wt $\mathrm{H}_{2} \mathrm{O}$ in lunar volcanic glasses and inferred much higher $\mathrm{H}_{2} \mathrm{O}$

35 contents in the pre-degassed magma. In a follow-up study, (Hauri et al., 2011) analyzed

36 olivine-hosted melt inclusions from lunar pyroclastic glass deposit 74220 ("orange glass")

37 sampling a pre-eruptive magma and found upwards of hundreds of ppm wt $\mathrm{H}_{2} \mathrm{O}$, confirming

38 the earlier inference of high water contents for the source magma. These discoveries have

39 motivated a number of subsequent investigations intended to reevaluate the abundance and

40 distribution of lunar water.

41

42 (Karato, 2013) reanalyzed the lunar geophysical observables, exploiting the high sensitivity

43 of electrical conductivity to the presence of protons to infer bulk $\mathrm{Moon}_{2} \mathrm{O}$ abundances of

44 10-100 ppm wt. (Sharp et al., 2010) observed a wide variation in the chlorine isotopic

45 composition of lunar samples and argued that such variation was due to a dearth of $\mathrm{H}_{2} \mathrm{O}$ in

46 the host lava and that the water content of the lunar mantle was constrained to $<0.1 \mathrm{ppm}$ wt. 
47 In a subsequent publication, (Sharp et al., 2013) showed that rapid degassing of $\mathrm{H}_{2}$ could

48 dehydrate lunar magmas and reconcile much more hydrous magma compositions with the

49 anhydrous conditions inferred by the chlorine isotopic data. (Hui et al., 2013) measured $\mathrm{H}_{2} \mathrm{O}$

50 contents in plagioclase grains in anorthosite and troctolite from the lunar crust, inferring an

51 initial water content of $\sim 320 \mathrm{ppm}$ wt for the lunar magma ocean from which these grains

52 presumably crystallized. (Albarède et al., 2015) measured $\mathrm{Zn}, \mathrm{Rb}$ and $\mathrm{K}$ abundances in a

53 range of lunar samples, constructed a volatility scale, extrapolated the behavior of

54 moderately volatile elements to $\mathrm{H}$ and concluded that the water content of the bulk Moon is

$55 \leq 1$ ppm wt. Finally, (Chen et al., 2015) analyzed melt inclusions from a range of mare

56 basalts and found $\mathrm{H}$ contents spanning 5-100 times less than that measured by (Hauri et al.,

57 2011), interpreted this range as a signature of degassing and inferred minimum $\mathrm{H}_{2} \mathrm{O}$

58 concentrations for the primitive lunar mantle of $110 \mathrm{ppm}$ wt.

60 The range in the inferred lunar water abundances attests to the uncertainties in interpreting

61 the lunar volatile record. For sample studies, this uncertainty can arise from: (i) the question

62 of whether the samples in question are characteristic or anomalous in the lunar interior, (ii)

63 an incomplete knowledge of mineral-melt partition coefficients necessary to infer magma

64 compositions from crystalline samples, and (iii) the process of degassing, which, for

65 extrusive volcanism, can eliminate the vast bulk of the inventory of volatiles in magmas, but

66 leave a record from which the history is difficult to reconstruct. Geophysical studies have

67 their own uncertainties; for example, interpretation of the observed electrical conductivity

68 and tidal dissipation in the lunar interior is subject to uncertainty partly due to an incomplete

69 understanding of the sensitivity of the observables to water contents and partly due to an 
70 incomplete knowledge of the values of the geophysical observables themselves (Karato,

71 2013). Such uncertainty allows a variety of inferences to be made from the observable lunar

72 volatile record, with recent inferences ranging from 1 ppm wt $\mathrm{H}_{2} \mathrm{O}$ (Albarède et al., 2015) to

73110 ppm wt (Chen et al., 2015). For the purposes of this study, we assume that the bulk

74 lunar $\mathrm{H}$ abundances are within this range.

76 Here, we investigate the question of the origin of lunar water: is the measured $\mathrm{H}$ a remnant

77 of primordial hydrogen inherited at birth or is it implanted via late-accretionary impacts by,

78 perhaps, water-rich impactors? The discovery of indigenous lunar water has come amidst

79 modern isotopic observations that provide new evidence for a "terrestrial" origin of the lunar

80 material (Kruijer et al., 2015; Pahlevan, 2014; Touboul et al., 2015; Young et al., 2016)

81 motivating new developments to the giant impact hypothesis (Canup, 2012; Cuk and

82 Stewart, 2012; Pahlevan and Stevenson, 2007; Pahlevan et al., 2011) and rendering possible

83 the inheritance of lunar water from the proto-Earth. Motivated by the nearly closed-system

84 behavior of hydrogen in the post-impact Earth-disk system (Nakajima and Stevenson, 2014),

85 we investigate whether the processes accompanying lunar origin can reproduce the bulk

86 elemental abundances recently inferred for the lunar interior. We address this question by

87 constructing a model capable of calculating snapshots of the evolution of the proto-lunar

88 disk and the equilibrium partitioning of hydrogen and its isotopes between the proto-lunar

89 liquid and co-existing vapor to gain insight into the behavior of $\mathrm{H}$ in the aftermath of the

90 Moon-forming impact. If the "water" being measured is indeed primordial (i.e. inherited at

91 birth), then its isotopic composition can be used to constrain the process of volatile depletion

92 with the advantage that hydrogen isotopes may exhibit significant equilibrium fractionation 
93 even at the high temperatures encountered after the giant impact (see Section 4.2). While a

94 detailed understanding of the processes that established the lunar volatile abundances is - at

95 present - non-existent, the process of liquid-vapor partitioning illustrated here must play a

96 role in any satisfactory scenario of volatile depletion. In Section 2, we describe the adopted

97 disk model. Section 3 covers the thermodynamic model we use to characterize high-T major

98 element silicates - and the chemical conditions they establish - in the proto-lunar disk, and

99 the modeled behavior of hydrogen as a passive tracer. In Section 4, results of elemental and

100 isotopic partitioning between the silicate vapor atmosphere and an underlying disk liquid

101 layer are presented. In Sections 5 and 6, the implications of these results for the origin of

102 lunar water are discussed and the conclusions of the study are summarized.

103

\section{2. Disk Model}

105 At present, only one evolutionary model of the proto-lunar disk has been developed that 106 attempts to make a connection between a disk process and a chemical or isotopic signature

107 in the lunar material (Canup et al., 2015). Such an evolutionary model is beyond the scope

108 of the present work. Instead, here we describe a physical-chemical model that permits 109 calculation of snapshots of the disk evolution, including the physical and chemical

110 conditions (e.g. $T, f_{2}$ ) that determine trace element and isotopic partitioning between the

111 liquid layer and the atmosphere as a function of the thermal state (Figure 1). With this

112 model, we can explore the behavior of tracers for the full range of conditions encountered in

113 the proto-lunar disk during its lifetime. 


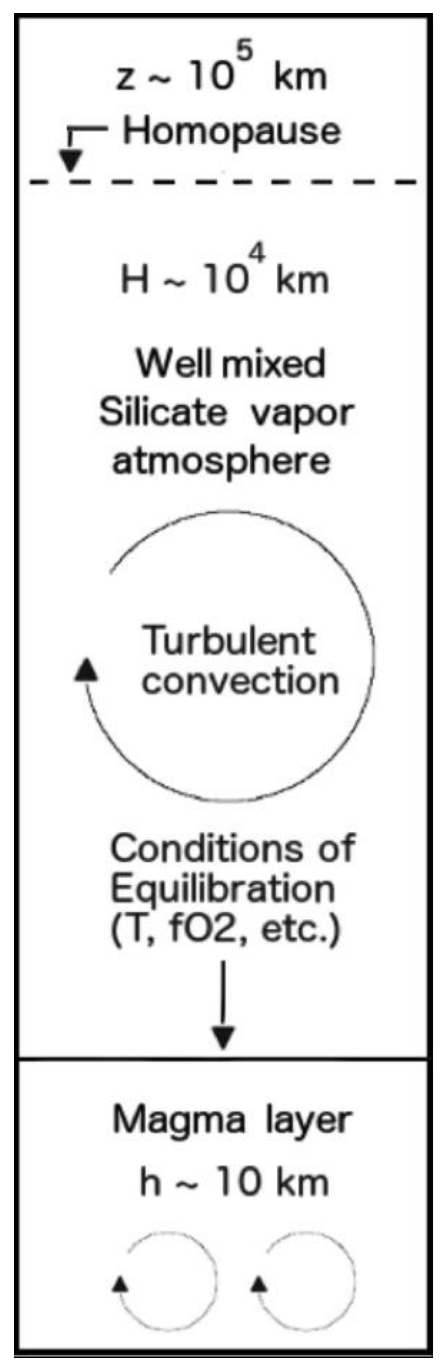

Fig. 1. A schematic diagram of a proto-lunar disk column, with a midplane liquid layer, a liquid-vapor interface, and an overlying atmosphere. The physical and chemical conditions at the interface (e.g. $\mathrm{T}, \mathrm{fO}_{2}$ ) determine the partitioning and therefore the composition of the liquid layer and complementary atmosphere. The proto-lunar liquid is assumed to become the lunar magma ocean liquid without further fractionation. The parameter that characterizes the thermal state is the mass fraction of the atmosphere $\left(f_{v}\right)$ and can vary between $0-1$. Vigorous (convective and other) fluid motions ensure that the vapor atmosphere is largely well-mixed and the homopause - above which vapor species can gravitationally separate according to distinct scale heights - appears only at very high altitudes. 
114 The physical model is of a 1-dimensional stratified column of disk material with a

115 convective liquid layer near the mid-plane, a liquid-vapor interface, and an overlying

116 convective atmosphere. The partitioning calculations here pertain to the conditions at the

117 liquid-vapor interface, as it is this setting where the composition of the liquid layer and

118 overlying vapor atmosphere may be determined. The two reservoirs (the magma layer and

119 atmosphere) are expected to chemically equilibrate on a short timescale for two reasons: (1)

120 convective turnover timescales are short relative to the lifetime of the proto-lunar disk,

121 which is $\sim 10^{2}-10^{3}$ years (Pahlevan and Stevenson, 2007) and (2) on the modern Earth, where

$122 \mathrm{pCO}_{2}$ equilibration between liquid water oceans and the atmosphere occurs on a timescale of

$123 \sim 10^{2}$ years (Archer et al., 2009), the exchange is mediated by bubble plumes (Asher et al.,

124 1996). That the proto-lunar magma layer co-exists with an overlying vapor pressure

125 atmosphere implies that the liquid near the interface will be boiling. An argument from

126 analogy with the modern Earth suggests that this feature of the liquid-vapor interface will

127 shorten equilibration timescales further. To calculate equilibrium partitioning, we need an

128 expression for the pressure of equilibration - determined by the atmospheric overburden - as

129 a function of the disk parameters. We assume vertical hydrostatic equilibrium:

$$
\underline{1} \frac{d p}{d z}=\frac{G M_{E}}{r^{3}} Z
$$

131 where $\rho$ is the density of the vapor, $p$ is the pressure, $z$ is the height above the mid-plane, $G$

132 is the gravitational constant, $M_{E}$ is the mass of the Earth and $r$ is the cylindrical distance

133 from Earth's spin axis. Following (Ward, 2012), we assume that the vertical component of

134 Earth gravity dominates over the disk self-gravity. To good approximation, the equation of 
135 state for the overlying vapor atmosphere can be written:

$$
p=k T /
$$

137 where $k$ is Boltzmann's constant, $T$ is the temperature, and $\mu$ is the mean molecular weight 138 of the vapor. Prior works have shown that the two-phase disk is nearly isothermal vertically, 139 i.e. 4 orders of magnitude of pressure variation can be accommodated with a 2-fold change 140 in the temperature (Thompson and Stevenson, 1988). For simplicity, we adopt an isothermal 141 atmospheric vertical structure. Combining (1) and (2) and integrating, we have:

$$
\begin{aligned}
& (z)={ }_{\text {int }} \exp \left(z^{2} / H^{2}\right) \\
& H=\sqrt{2} C_{s} /
\end{aligned}
$$

144 where $\rho_{\text {int }}$ represents the interface density, $H$ is the scale height, $C_{S}$ is the isothermal sound 145 speed $\left[=(\mathrm{kT} / \mathrm{m})^{1 / 2}\right]$ and $\Omega$ is the Keplerian angular frequency $\left[=\left(\mathrm{GM}_{\mathrm{E}} / \mathrm{r}^{3}\right)^{1 / 2}\right]$ at disk radius $r$.

146 The surface density of the vapor atmosphere can be expressed as:

$$
{ }_{v}=(z) d z
$$

148 For the density structure described in equation (3), integration yields ${ }_{v}=\sqrt{ }{ }_{\text {int }} H$, with

$149 \rho_{\text {int }}$ the interface gas density, which, together with equations (2) and (4), yields an expression

150 for the liquid-vapor interface pressure:

$$
P_{\text {int }}=\frac{1}{\sqrt{2}} f_{v}{ }_{T} C_{s}
$$

152 where $f_{v}$ is the atmospheric mass fraction of the column (column $=$ atmosphere + liquid 153 layer) and $\sigma_{T}$ is the total column surface density $\left(\sigma_{v}=f_{v} \sigma_{T}\right)$. It is this relationship between the 154 equilibration pressure $\left(P_{i n t}\right)$ and column vapor fraction $\left(f_{v}\right)$ that determines the 155 thermodynamic partitioning described below. This calculation of the pressure - while 
156 neglecting the liquid layer - well-approximates the liquid-vapor interface pressure in the

157 relevant limit where the vertical thickness of the liquid layer is much less than the 158 atmospheric scale height, $\mathrm{H}$.

160 To make a connection with observables, we must relate the calculated composition of the 161 proto-lunar disk liquid and atmosphere to that of the lunar magma ocean. Motivated by the 162 evolutionary model of the proto-lunar disk described by (Ward, 2012), we assume that the 163 disk liquid whose composition is calculated here becomes the lunar magma ocean without

164 further fractionation during the process of lunar accretion (see Section 5.2). In this picture,

165 the liquid layer undergoes "patch" instabilities in which patches of the disk clump via self-

166 gravity before being sheared apart by tidal forces, while the overlying atmosphere remains

167 gravitationally stable. The resulting viscous dissipation near the midplane leads to spreading

168 of the disk liquid beyond the Roche radius where the same process of self-gravity can

169 proceed to generate moonlets (Salmon and Canup, 2012). That the condensation of the lunar

170 material occurs at higher pressures than the triple point of the major silicate components

171 (Nagahara et al., 1994) implicates liquids in the proto-lunar disk, a feature that renders the

172 proto-lunar material more retentive with respect to hydrogen than corresponding solar

173 nebula condensates (Karato, 2013). We select disk parameters $\left(C_{S}=10^{3} \mathrm{~m} / \mathrm{s}, \Omega=2.2 \times 10^{-4}\right.$

$174 \mathrm{~s}^{-1}$ ) appropriate to conditions at the Roche radius due to the expectation that the proto-lunar

175 liquid undergo last equilibration with a vapor atmosphere in this setting before fragmenting

176 into moonlets and accreting onto the proto-Moon (Salmon and Canup, 2012).

\section{Thermodynamic Model}




\subsection{Major elements}

180 We use a 2-phase binary olivine $\left[(\mathrm{Fe}, \mathrm{Mg})_{2} \mathrm{SiO}_{4}\right]$ thermodynamic model recently developed

181 to study liquid-vapor fractionation in the aftermath of the giant impact (Pahlevan et al.,

182 2011) to capture the physical and chemical conditions prevailing during the thermal

183 evolution of the melt-vapor proto-lunar disk. This choice is motivated by the fact that the

184 Moon is known to be composed primarily of ferromagnesian silicates. In brief, the model 185 describes high-temperature silicate liquids as a binary solution between olivine end-

186 members and silicate vapors as a mixture of ideal gases consisting of the vapor species

$187 \mathrm{MgO}(v), \mathrm{Mg}(\mathrm{v}), \mathrm{FeO}(\mathrm{v}), \mathrm{Fe}(\mathrm{v}), \mathrm{SiO}_{2}(\mathrm{v}), \mathrm{SiO}(\mathrm{v}), \mathrm{Si}(\mathrm{v}), \mathrm{O}_{2}(\mathrm{v})$ and $\mathrm{O}(\mathrm{v})$. Ionized species are

188 known to be present at only trace levels in this environment (Visscher and Fegley, 2013) and

189 are neglected. Input parameters for the model are the total column composition, which we

190 set equal to that of the terrestrial mantle $(\mathrm{Fe} / \mathrm{Fe}+\mathrm{Mg}=0.1)$, the column specific entropy $(S=$

$1910.546-1.092 \mathrm{~kJ} / \mathrm{mol} . \mathrm{K}$, where mol refers to moles of olivine units or silicon atoms) which is

192 varied to capture the range of possible thermal states from fully vaporized to fully

193 condensed, and the pressure of equilibration determined by the overlying atmosphere

194 (Equation 6). Using these relations, we solve for the temperature $(T)$, the column vapor

195 fraction $\left(f_{V}\right)$, the specific entropy $\left(S_{L} S_{V}\right)$ and composition $\left(X_{L}, X_{V}\right)$ of the disk liquid layer

196 and atmosphere, and the partial vapor pressure of each of nine species $\left(P_{i}\right)$ for the full range

197 of conditions encountered in the proto-lunar disk. Results from major element calculations

198 include equilibration temperature $(\mathrm{T})$ and the oxygen fugacity $\left(\mathrm{fO}_{2}\right)$ characterizing the

199 liquid-vapor equilibrium that can then be used to calculate the trace element and isotopic 200 partitioning as a function of the thermal state (expressed in terms of, e.g. the entropy or 201 vapor fraction of the column). The main assumption in such an approach is that the liquid 
202 layer and overlying atmosphere are in thermodynamic equilibrium. We vary the disk silicate 203 composition (Fe/Fe+Mg) in a plausible range (0.1-0.2) (Khan et al., 2007; Warren, 2005) to 204 test for sensitivity of the results and find that final $\mathrm{H}$ abundances in the proto-lunar liquids 205 vary in this range by less than 10 percent. The temperatures of equilibration between the 206 liquid layer and atmosphere that we consider (4,200-3,100 K) span the range from nearly 207 full vaporized $\left(f_{v}>0.99\right)$ to nearly fully condensed $\left(f_{v}<0.01\right)$ states.

209 3.2. Trace elements $-\mathrm{H}$

210 With the thermodynamic conditions in the disk - determined by the major elements -

211 calculated, the behavior of hydrogen as a trace element can be described. Experimental work 212 on terrestrial magmas has shown that, in the low-concentration limit, the water fugacity in

213 equilibrium with hydrous silicate melts follows a solubility law of the form $f_{H 2 O} \propto x_{L}^{2}$

214 (Hamilton et al., 1964) where $f_{H 2 O}$ is the water fugacity and $x_{L}$ the mass fraction of water 215 dissolved in the co-existing melt. Such a solubility law is widely interpreted to reflect melt 216 dissolution of water vapor via reaction with oxygen ions in the silicate melt to produce $\mathrm{OH}$ 217 groups, a proposition supported by infrared spectroscopic studies of hydrogen speciation in 218 silicate glasses (Stolper, 1982). Because the water abundance in proto-lunar liquids are - by 219 experimental standards - low $(<0.1 \mathrm{wt} \%)$ and the temperatures high, we expect hydrogen 220 speciation in proto-lunar liquids to be dominated by $\mathrm{OH}$ rather than dissolved molecular $221 \mathrm{H}_{2} \mathrm{O}$ (Stolper, 1989). Recent experimental work has also shown that $\mathrm{H}_{2}$ is likely to be a

222 minor species in melts at the low pressures $(<0.1 \mathrm{GPa})$ and low total $\mathrm{H}$ contents prevailing 223 in proto-lunar liquids, even for reducing proto-lunar magmas (Hirschmann et al., 2012). 224 Finally, while no experimental data exists for the solubility of "water" (as $\mathrm{OH}$ ) in silicate 
225 magmas at the temperatures $(3,100-4,200 \mathrm{~K})$ and melt compositions of relevance, existing

226 data indicates slightly retrograde (i.e. decreasing with temperature) solubility, with a

227 relatively weak sensitivity to temperature and melt composition (Burnham and Jahns, 1962;

228 Karsten et al., 1982; Yamashita, 1999). Accordingly, we adopt for the solubility of water in

229 proto-lunar liquids:

$$
P_{\mathrm{H}_{2} \mathrm{O}}(\text { bars })=104 \quad \frac{x_{L}^{\mathrm{H}_{2} \mathrm{O}}}{0.01} \div
$$

231 as measured in a basaltic melt at $1370 \mathrm{~K}$ (Hamilton et al., 1964). Despite the imprecise

232 match of the melt composition to ultramafic proto-lunar melts and a $\sim 3 \mathrm{x}$ difference with

233 temperatures prevailing in the proto-lunar system, we do not explicitly model the

234 dependence of water solubility with available thermodynamic models (Silver and Stolper,

235 1985). Assuming that the observed insensitivity of solubility to temperature and composition

236 extends to the relevant temperatures and compositions, such variations, while not negligible,

237 represent refinements to the picture here described. As in the analogous terrestrial magma

238 ocean and atmosphere system (Fegley and Schaefer, 2014), experimental determination of

239 water solubility in ultramafic silicate melts at the temperatures of relevance will help to

240 clarify the role of temperature and compositional dependence on equilibrium $\mathrm{H}$ dissolution

241 in the proto-lunar disk.

243 The thermodynamic behavior of H-bearing vapors can be readily articulated. The behavior

244 of $\mathrm{H}$ in the vapor phase of the proto-lunar disk is distinctly different from that in vapors in

245 modern magmatic systems in two important respects. First, as noted above, the temperatures

246 are 2-3 times higher in proto-lunar vapors than modern magmatic vapors, and this has the 247 effect of favoring thermal dissociation of molecules. Hence, in addition to the usual $\mathrm{H}_{2} \mathrm{O}-\mathrm{H}_{2}$ 
248 equilibrium of magmatic gases determined by the oxygen fugacity of co-existing melts, we 249 must consider dissociation reactions such as:

$$
\mathrm{H}_{2} \mathrm{O}(v)=\mathrm{OH}(v)+H(v)
$$

$$
K_{8}=\frac{P(O H) \quad P(H)}{P\left(H_{2} O\right)}=\exp \left(\Delta G_{8} / R T\right)
$$

252 An equilibrium speciation reaction and associated equilibrium constant is written for each 253 reaction in Table 1 relating the partial pressures of $\mathrm{H}_{2} \mathrm{O}(\mathrm{v}), \mathrm{H}_{2}(\mathrm{v}), \mathrm{OH}(\mathrm{v})$ and $\mathrm{H}(\mathrm{v})$.

Table 1. The standard entropy and enthalpy of reactions $\left(\operatorname{lnK}=\Delta \mathrm{G}^{\circ} / \mathrm{RT}, \Delta \mathrm{G}^{\circ}=\Delta \mathrm{H}^{\circ}-\right.$ $\mathrm{T} \Delta \mathrm{S}^{\circ}$ ) that determine the vapor speciation of hydrogen in a silicate vapor atmosphere at thermodynamic equilibrium. Thermodynamic data are from (38). For the calculations, we consider a number of $\mathrm{H}$-bearing silicate molecules: $\mathrm{Fe}(\mathrm{OH})_{2}, \mathrm{Si}(\mathrm{OH})_{4}, \mathrm{Si}(\mathrm{OH})_{2}, \mathrm{SiOH}, \mathrm{SiH}_{4}$, $\mathrm{SiH}, \mathrm{Mg}(\mathrm{OH})_{2}, \mathrm{MgOH}$ and $\mathrm{MgH}$. Only $\mathrm{MgOH}(\mathrm{v})$ is present in appreciable abundances in the proto-lunar disk and is therefore explicitly included in the calculations.

\begin{tabular}{|l|l|l|}
\hline Reaction & $\Delta \mathrm{S}^{\circ}(\mathbf{J} / \mathbf{m o l} . \mathbf{K})$ & $\Delta \mathbf{H}^{\circ}(\mathbf{k J} / \mathbf{m o l})$ \\
\hline $\mathrm{H}_{2} \mathrm{O}(\mathrm{v})=\mathrm{H}_{2}(\mathrm{v})+1 / 2 \mathrm{O}_{2}(\mathrm{v})$ & 58.1 & 250.2 \\
\hline $\mathrm{H}_{2} \mathrm{O}(\mathrm{v})=\mathrm{OH}(\mathrm{v})+\mathrm{H}(\mathrm{v})$ & 132.2 & 514.1 \\
\hline $\mathrm{H}_{2}(\mathrm{v})=2 \mathrm{H}(\mathrm{v})$ & 121.4 & 453.6 \\
\hline $\mathrm{MgOH}(\mathrm{v})=\mathrm{Mg}(\mathrm{v})+\mathrm{OH}(\mathrm{v})$ & 104 & 346.6 \\
\hline
\end{tabular}

254 Indeed, as discussed in the next section, in contrast to magmatic systems, $\mathrm{OH}(\mathrm{v})$ and $\mathrm{H}(\mathrm{v})$

255 are important species in the silicate vapor atmosphere of the proto-lunar disk. Secondly, 256 because of the high temperatures, the vapor pressure of major element silicate vapors in this 257 system is significant and, for most of the thermal history of the disk, dominant. Hence, in 
258 contrast to magmatic systems, reactions between H-bearing vapor species and major element

259 silicate vapors such as $\mathrm{Mg}(\mathrm{v})$ must be considered. In addition to the simple O-H vapor 260 chemistry, we have reactions such as:

$$
\operatorname{MgOH}(v)=\operatorname{Mg}(v)+O H(v)
$$

$$
K_{10}=\frac{P(M g) P(O H)}{P(M g O H)}=\exp \left(\Delta G_{10} / R T\right)
$$

263 with $\mathrm{P}(\mathrm{Mg})$ adopted from the major element calculations. We list all H-bearing silicate

264 vapor molecules included in speciation calculations and thermodynamic values used for the 265 Gibbs energy of reactions in Table 1.

267 With relations for both heterogeneous (Equation 7) and homogeneous (Equation 9 and 268 equivalent for all reactions in Table 1) equilibria for the liquid and vapor, the 269 thermodynamic description of hydrogen as a passive tracer is complete. To calculate the 270 coupled speciation and partitioning of $\mathrm{H}$, we write statements of mass balance between the 271 liquid and vapor:

$$
x_{H}=F_{v} x_{v}+\left(1 \quad F_{v}\right) x_{L}
$$

273 where $x_{H}, x_{V}$ and $x_{L}$ are the total mass fraction of $\mathrm{H}$ in the lunar disk, vapor atmosphere, and 274 silicate liquid layer, respectively, and $F_{V}$ is the column vapor mass fraction. In the 275 calculations presented here, we adopt $\mathrm{x}_{\mathrm{H}}=10^{-5}-10^{-3}$ (or equivalently $\left[\mathrm{H}_{2} \mathrm{O}\right]=90-9,000 \mathrm{ppm}$ $276 \mathrm{wt}$ ) and discuss the rationale for this parameter choice for proto-lunar disk $\mathrm{H}$ abundances $277\left(\mathrm{x}_{\mathrm{H}}\right)$ at the end of this section. For the mass fraction of $\mathrm{H}$ in the vapor, we have:

$$
x_{V}^{H}=\frac{{ }_{i}^{n_{i}} P_{i}}{P}
$$


279 where the summation is over all hydrogen bearing species and with $n_{i}$ the number of 280 hydrogen atoms contributed by different vapor species with partial pressure $P_{i}$ and $\mu$ and $P$ 281 representing the mean molecular weight (in $\mathrm{amu}$ ) and total pressure of the silicate vapor 282 derived from major element calculations. Finally, for the mass fraction of $\mathrm{H}$ in the liquid, we 283 have:

$$
x_{L}^{H}=\frac{2}{18} x_{L}^{H_{2} O}
$$

285 where the conversion factor arises because $\mathrm{H}$ melt abundances in solubility laws (e.g. 286 Equation 7) are typically expressed as weight percent of equivalent water whereas our 287 statements of mass balance are expressed as mass fractions of hydrogen. With equations 288 representing the solubility law (7), speciation reactions (9), (11) and two others for gas phase 289 equilibria (Table 1), and statements of mass balance in (12)-(14), the system is fully 290 specified. We simultaneously solve for the mole fraction of hydrogen species in the vapor $291\left(\mathrm{xH}_{1} \mathrm{xH}_{2}, \mathrm{xOH}, \mathrm{xH}_{2} \mathrm{O}, \mathrm{xMgOH}\right)$ as well as the mass fraction of hydrogen in the silicate 292 liquid $\left(x_{L}^{H}\right)$ and silicate vapor $\left(x_{V}^{H}\right)$.

294 What is the total $\mathrm{H}\left(\right.$ or $\left.\mathrm{H}_{2} \mathrm{O}\right)$ abundance $\left(\mathrm{x}_{\mathrm{H}}\right)$ in the proto-lunar disk? While this value is not 295 precisely known, several features of the Earth-Moon system constrain the likely range of 296 disk $\mathrm{H}$ abundances. First, the latest isotopic data continue to support a terrestrial provenance 297 of the lunar material (Kruijer et al., 2015; Pahlevan, 2014; Touboul et al., 2015; Young et 298 al., 2016). Hence, we can expect that the proto-lunar disk acquired - at minimum - the $\mathrm{H}$ 299 abundances of the proto-Earth mantle at the time of the Moon-forming event. Second, both 300 dynamical and cosmochemical lines of evidence suggest that the Earth's water was largely 301 accreted before lunar origin, i.e. the proto-Earth at the time of the Moon-forming impact was 
302 significantly "wet". These lines of evidence are as follows: (a) dynamical: the small value of 303 the lunar inclination suggests that the Moon-forming giant impact was a "late" event in 304 Earth accretion history, resulting in a nearly fully-accreted Earth with a mass likely near $3050.99 \mathrm{M}_{\mathrm{E}}$ (Pahlevan and Morbidelli, 2015). Moreover, the Moon-forming impact is a local 306 dynamical event in the inner Solar System and there is no known reason that the nature of

307 Earth-forming impactors would fundamentally change with the occurrence of this event. For 308 this reason, models of planetary accretion consistently find that most of the Earth's water 309 was accreted before the late veneer, i.e. before the Earth had acquired $0.99 \mathrm{M}_{\mathrm{E}}\left(\mathrm{O}^{\prime}\right.$ Brien et 310 al., 2014; Rubie et al., 2015), (b) cosmochemical: the mass accreted to the Earth after the 311 Moon-forming event (the "late veneer") is constrained by the isotopic composition of the 312 silicate Earth and Moon to be a small fraction of the Earth's mass, likely $0.01 \mathrm{M}_{\mathrm{E}}$ or less 313 (Jacobson et al., 2014). Such a small mass can deliver only a fraction of Earth's inventory of 314 volatiles elements (e.g. that of ${ }^{204} \mathrm{~Pb}$ ) and the geochemical coherence of volatile elements 315 suggests that a similar argument can be made for other elements whose terrestrial budgets 316 are not precisely known (e.g. H). The cosmochemical arguments for substantial pre-lunar 317 terrestrial accretion of volatile elements are summarized in (Morbidelli and Wood, 2015).

318 Motivated by the observations indicating that the proto-lunar disk was sourced from the

319 Earth and that the silicate Earth's $\mathrm{H}$ budget was largely established prior to the Moon320 forming event, we adopt $x_{H}=10^{-5}-10^{-3}$ (i.e. $\left[\mathrm{H}_{2} \mathrm{O}\right]=90-9000 \mathrm{ppm} w \mathrm{w}$ ), a range that 321 encompasses recent inferences of the $\mathrm{H}$ budget of the silicate Earth (Hirschmann, 2006; 322 Marty, 2012).

\section{4. Results}




\subsection{Vapor speciation}

326 The H-vapor speciation in the proto-lunar disk is found to be distinct from other petrologic

327 and nebular systems. Speciation in the $\mathrm{O}-\mathrm{H}$ system in this environment is dominated by

$328 \mathrm{OH}(\mathrm{v})$ and $\mathrm{H}(\mathrm{v})$ rather than the more familiar magmatic species $\mathrm{H}_{2} \mathrm{O}(\mathrm{v})$ and $\mathrm{H}_{2}(\mathrm{v})$ for nearly

329 the full range of conditions encountered in the proto-lunar disk (Figure 2).

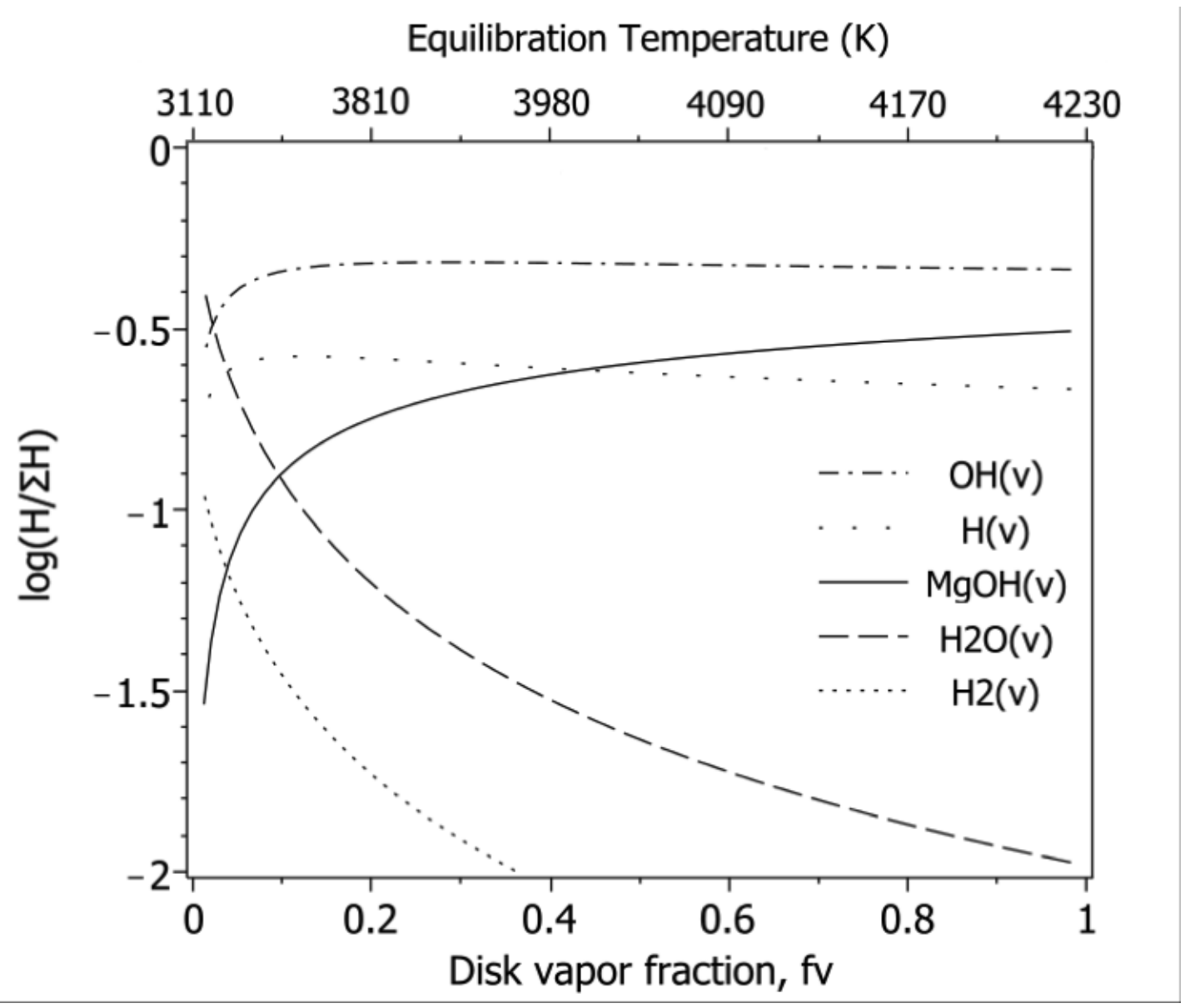

Fig. 2. The relative abundances of H-bearing vapor species in the proto-lunar disk as a function of the disk vapor fraction and equilibration temperature for a total disk $\left[\mathrm{H}_{2} \mathrm{O}\right]=900$ ppm wt. $\mathrm{OH}(\mathrm{v})$ dominates the vapor-phase speciation for the thermal state $(f v \sim 0.2)$ generated via the "standard" giant impact (Canup and Asphaug, 2001) as well as more 
energetic (fv 0.5-0.9) high-angular momentum impacts (Canup, 2012; Cuk and Stewart, 2012). Both $\mathrm{H}_{2}(\mathrm{v})$ and $\mathrm{H}_{2} \mathrm{O}(\mathrm{v})$ are trace vapor species until the silicate vapor has undergone near-complete condensation $(f v \sim 0)$. The pressure of equilibration is 36 bars at full vaporization $\left(\mathrm{f}_{\mathrm{v}}=1\right)$ and decreases linearly with decreasing vapor fraction (Equation 6).

330 Both higher temperatures and lower mixing ratios of $\mathrm{H}$ in the silicate-rich vapor favor 331 dissociation of $\mathrm{H}_{2} \mathrm{O}(\mathrm{v})$ and $\mathrm{H}_{2}(\mathrm{v})$ relative to modern magmatic systems. The behavior of 332 hydrogen in this system also differs in important respects from that in the solar nebula, 333 where the most abundant equilibrium $\mathrm{H}$-bearing species at 2,000 $\mathrm{K}$ are $\mathrm{H}_{2}$ and $\mathrm{H}_{2} \mathrm{O}$ 334 (Larimer, 1967; Lord, 1965). Nebular equilibrium is distinct not only because of the lower 335 temperatures but also the distinct abundances. Since the $\mathrm{H} / \mathrm{Mg}$ ratio of the solar nebula is $336 \sim 10^{3}$, conclusions about nebular speciation of $\mathrm{H}$ can be reached without a consideration of $337 \mathrm{Mg}$-bearing species. In the silicate proto-lunar disk, by contrast, the situation is reversed 338 with $\mathrm{Mg} / \mathrm{H} \sim 10^{3}$ and $\mathrm{Mg}$-bearing vapor molecules (e.g. $\mathrm{MgOH}$ ) have the potential to 339 sequester a significant fraction of the trace $\mathrm{H}$ abundance in proto-lunar vapors. A similar 340 situation exists for H-bearing $\mathrm{Si}$ - and Fe-species (e.g. SiH). Accordingly, in our calculations,

341 we include metal-bearing molecules bonded with $\mathrm{H}$ for which thermodynamic data exist

342 (Table 1). We find that $\mathrm{MgOH}(\mathrm{v})$ is an important carrier of hydrogen in the proto-lunar disk 343 and more abundant than $\mathrm{H}_{2} \mathrm{O}(\mathrm{v})$ and $\mathrm{H}_{2}(\mathrm{v})$ at even moderate degrees of silicate vaporization $344\left(f_{v}>0.1\right)$. As condensation proceeds, the dominant $\mathrm{H}$-bearing species transition from $345 \mathrm{MgOH}(\mathrm{v}), \mathrm{OH}(\mathrm{v})$ and $\mathrm{H}(\mathrm{v})$ to primarily $\mathrm{H}_{2} \mathrm{O}(\mathrm{v})$ and $\mathrm{H}_{2}(\mathrm{v})$ as the silicate vapor atmosphere 346 transitions to a steam atmosphere (Figure 2) analogous to the steam atmosphere of the Earth 347 (Zahnle et al., 1988). The spectrum of vapor species present during the condensation has 
348 consequences for both partitioning (section 4.2) and isotopic fractionation (section 4.3).

350 4.2. Dissolution

351 How much hydrogen partitions into proto-lunar liquids? The vapor-phase speciation

352 reactions render $\mathrm{OH}(\mathrm{v}), \mathrm{H}(\mathrm{v})$ and $\mathrm{MgOH}(\mathrm{v})$ dominant hydrogen reservoirs in the proto-lunar

353 disk and, for a given hydrogen abundance, decrease the water vapor partial pressure and 354 water fugacity. Hence, in considering water dissolution into silicate liquids, such reactions

355 have the influence of shifting the equilibrium towards exsolution. Nevertheless, we find that

356 significant disk hydrogen (2-22\% of the total) remains dissolved in proto-lunar liquids 357 (Figure 3).

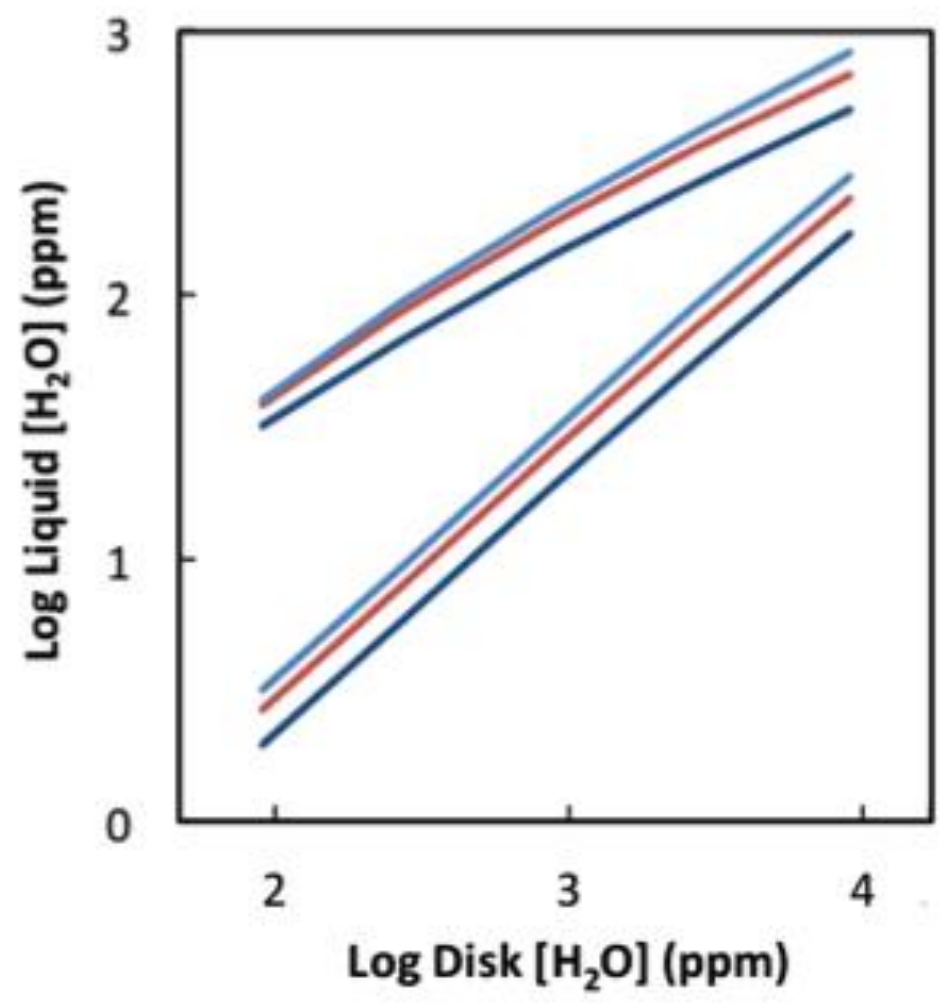


Fig. 3. Equilibrium $\mathrm{H}_{2} \mathrm{O}$ dissolution into proto-lunar liquids as a function of the total disk $\mathrm{H}_{2} \mathrm{O}$ abundance. Color denotes total disk surface density of $2 \times 10^{7} \mathrm{~kg} / \mathrm{m}^{2}$ (blue), $4 \times 10^{7}$ $\mathrm{kg} / \mathrm{m}^{2}$ (red), and $6 \times 10^{7} \mathrm{~kg} / \mathrm{m}^{2}$ (cyan). Higher surface density favors greater dissolution. The lower trio of curves represents the liquid $\mathrm{H}$ abundances at the onset of disk condensation $\left(f_{v}\right.$ 1) while the upper trio corresponds to conditions toward the end of condensation $\left(f_{v} \sim 0\right)$. The main cause of the offset between the trio of curves is the effect of vapor-phase speciation: predominantly $\mathrm{H}_{2} \mathrm{O}$ near full condensation, predominantly $\mathrm{OH}-\mathrm{MgOH}-\mathrm{H}$ at higher vapor fractions. $\mathrm{OH}$ is expected to dominate the $\mathrm{H}$ speciation in the liquid and the presence of other H-bearing liquid species would only make the liquid more retentive with respect to $\mathrm{H}$ than here calculated. The liquid $\mathrm{H}$ abundances is bounded by pairs of curves, implying significant H-retention into proto-lunar liquids (=0.02-0.22 of the total).

358 The high solubility of $\mathrm{H}$ in silicate melts translates into significant proto-lunar liquid $\mathrm{H}$

359 abundances despite the high temperatures, high degrees of vaporization and diverse range of

$360 \mathrm{H}$-bearing vapor species in the proto-lunar disk. For a range of total $\mathrm{H}$ contents for the proto-

361 lunar disk of 90-9,000 ppm wt $\mathrm{H}_{2} \mathrm{O}$, proto-lunar liquids with $\mathrm{H}_{2} \mathrm{O}$ concentrations of several

$362 \times 1-100 \mathrm{ppm} w \mathrm{w}$ arise. While the giant impact is often assumed to result in catastrophic near-

363 complete degassing of the lunar material, these calculations suggest that equilibrium

364 partitioning in a vapor atmosphere can result in significant retention of $\mathrm{H}$ in proto-lunar 365 liquids.

367 4.3. Equilibrium isotopic fractionation

368 Unlike potassium isotopes, which predominantly exist in atomic form in silicate vapors 369 (Visscher and Fegley, 2013) and are ionically bonded in the liquid, rendering near-zero 
370 equilibrium isotopic fractionation (personal communication, Edwin Schauble, 2009), $\mathrm{H}$ in

371 this system exists in a variety of bonding environments ranging from $\mathrm{OH}$ groups in the melt,

372 to water vapor, the hydroxyl molecule, magnesium hydroxide and molecular and atomic

373 hydrogen in the vapor. Significant differences in the bonding environment of an element

374 between two phases can cause significant equilibrium isotopic fractionation, even at the

375 temperatures encountered after the giant impact (Pahlevan et al., 2011). Such differences in

376 the bonding environment for hydrogen between the liquid and vapor can, therefore,

377 potentially fractionate the $\mathrm{H}$ isotopes even at the relevant high temperatures. Hence, if the

378 water being measured as $\mathrm{OH}$ in lunar samples is primordial, then its isotopic composition

379 can potentially be used to constrain the processes of lunar volatile depletion.

381 Unfortunately, isotopic fractionation factors for hydrogen in silicate melts at the relevant

382 temperatures do not - at present - exist. Moreover, existing experimental data for $\mathrm{H}$ isotope

383 fractionation in silicates at igneous temperatures (Dobson et al., 1989; Pineau et al., 1998)

384 does not exhibit the usual high-temperature behavior $\left(\ln B=a / T^{2}\right)$ ensuring no reliable

385 extrapolation to high temperatures at the present time. Nevertheless, equilibrium isotopic

386 fractionation between the vapor species $\mathrm{MgOH}(\mathrm{v}), \mathrm{H}_{2} \mathrm{O}(\mathrm{v}), \mathrm{OH}(\mathrm{v}), \mathrm{H}_{2}(\mathrm{v})$, and $\mathrm{H}(\mathrm{v})$ are

387 calculable and among the highest in nature. We can therefore gain insight into equilibrium

388 behavior of $\mathrm{H}$ isotopes in the proto-lunar disk by making the assumption that the bonding

389 environment for $\mathrm{OH}$ in silicate liquids can be approximated by that of the $\mathrm{OH}$ molecule in

390 the vapor. The problem is then reduced to calculating the isotopic fractionation between the 391 vapor species. 
393 The isotopic fractionation factor $(B)$ for $\mathrm{H}_{2} \mathrm{O}(\mathrm{v})$ and $\mathrm{H}_{2}(\mathrm{v})$ as a function of temperature has

394 been extensively studied experimentally and theoretically. We adopt the results of the

395 calculations of (Richet et al., 1977) for these molecules. $\mathrm{OH}(\mathrm{v})$ and $\mathrm{MgOH}(\mathrm{v})$, by contrast, 396 have received much less attention as isotopic molecules. The vibrational frequencies of these 397 molecules are known from spectroscopic (Chase et al., 1985) and ab initio (Koput et al., 398 2002) studies, rendering fractionation factors readily calculable. Here, following the 399 standard procedure (Urey, 1947), isotopic fractionation between molecules are calculated by 400 writing the appropriate exchange reactions between isotopic species:

$$
\begin{aligned}
& D(v)+O H(v)=H(v)+O D(v) \\
& K_{15}=\frac{Q(O D)}{Q(O H)} / \frac{Q(D)}{Q(H)}
\end{aligned}
$$

403 where $Q$ 's refer to partition functions whose ratios for isotopically substituted and normal 404 species can be expressed assuming harmonic vibrations:

$$
\frac{Q^{\prime}}{Q}=\frac{v_{i}^{\prime}}{v_{i}} \frac{e^{U_{i}^{\prime} / 2}}{e^{U_{i} / 2}} \frac{1 e^{U_{i}}}{1 e^{U_{i}^{\prime}}}
$$

406 where $v$ and $v^{\prime}$ are vibrational frequencies for the normal and isotopically substituted 407 molecules, respectively, with adopted values displayed in Table 2. 
Table 2 - Vibrational frequencies of isotopically normal and substituted molecules. Fractionation factors derived from these frequencies are plotted in Figure 4.

\begin{tabular}{|c|c|c|c|c|}
\hline $\begin{array}{c}\text { Vapor } \\
\text { Species }\end{array}$ & Mode (Degeneracy) & $\begin{array}{c}\text { Fundamental } \\
\text { Frequency }\left(\mathbf{c m}^{-\mathbf{1}}\right)\end{array}$ & $\begin{array}{c}\text { Substituted } \\
\text { Fundamental } \\
\text { Frequency }\left(\mathbf{c m}^{-\mathbf{- 1}}\right)\end{array}$ & Reference \\
\hline $\mathrm{OH}$ & Stretch (1) & 3735 & 2718 & (Chase et al., 1985) \\
\hline $\mathrm{MgOH}$ & Mg-O Stretch (1) & 750 & 737 & (Bunker et al., 1995) \\
\cline { 2 - 5 } & Bending mode (2) & 161 & 109 & (Koput et al., 2002) \\
\cline { 2 - 5 } & O-H Stretch (1) & 3851 & 2846 & \\
\hline
\end{tabular}

408 We follow this procedure for calculating the fractionation factors for both $\mathrm{OH}(\mathrm{v})$ and

$409 \mathrm{MgOH}(\mathrm{v})$. The main characteristic determining the isotopic composition of vapor species is

410 whether or not it features the high frequency $\mathrm{OH}$ stretch, which strongly concentrates

411 deuterium. For this reason, fractionation factors for $\mathrm{H}_{2} \mathrm{O}(\mathrm{v}), \mathrm{OH}(\mathrm{v})$ and $\mathrm{MgOH}(\mathrm{v})$ are very

412 similar and distinct from those for $\mathrm{H}_{2}(\mathrm{v})$ and $\mathrm{H}(\mathrm{v})$. $\mathrm{H}$ isotopic fractionation factors for the 413 vapor species are plotted in Figure 4. 


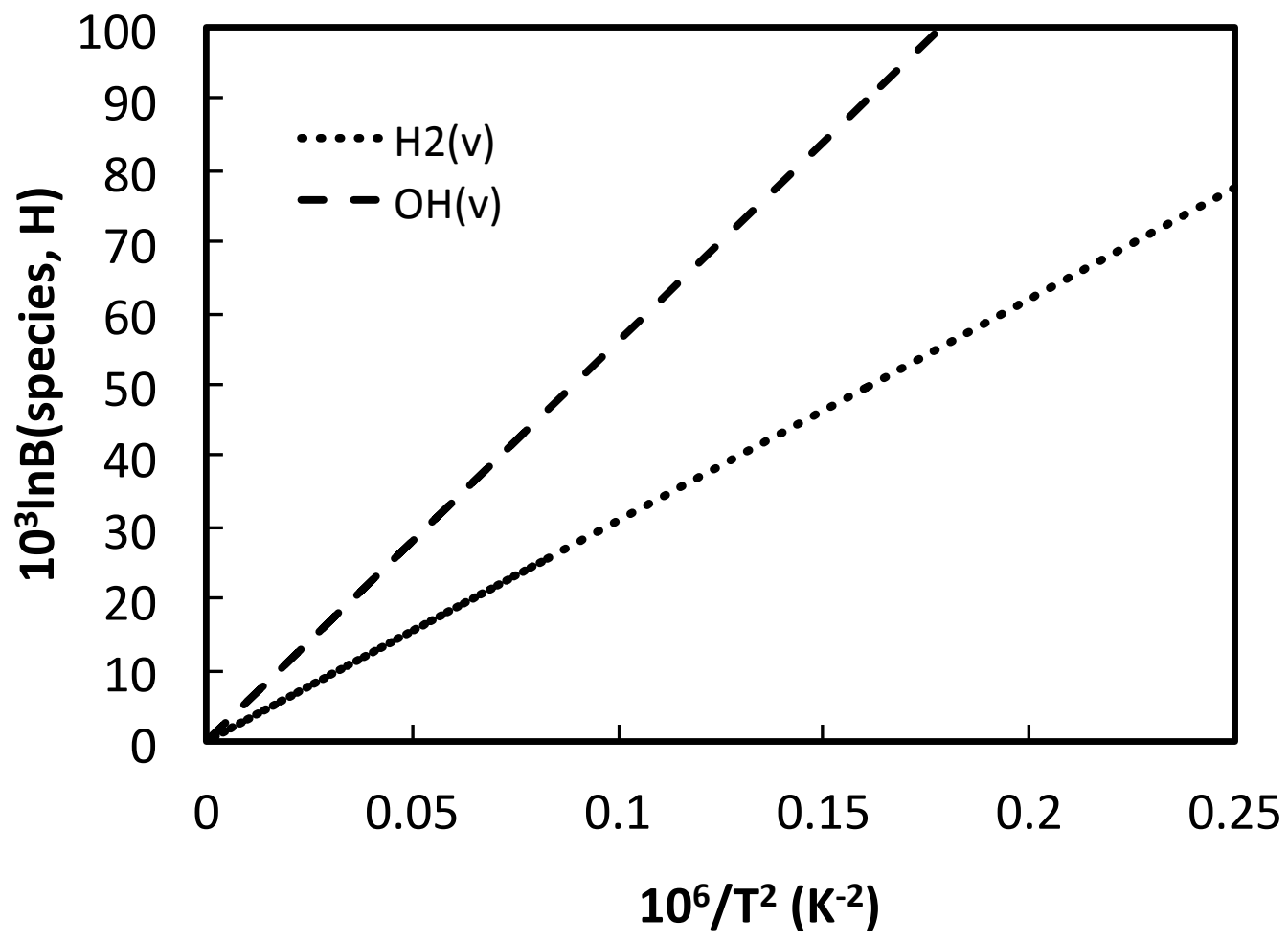

Figure 4 - Equilibrium isotopic fractionation between co-existing vapor species in the proto-lunar disk. The fractionation factor for $\mathrm{H}_{2}$ is adopted from (Richet et al., 1977). This calculation highlights the importance of $\mathrm{H}$-speciation for articulating the isotopic predictions of liquid-vapor equilibration. Adopted and calculated slopes $\left[=\operatorname{lnB} /\left(10^{6} / \mathrm{T}^{2}\right)\right]$ for $\mathrm{H}_{2} \mathrm{O}(\mathrm{v})$ and $\mathrm{MgOH}(\mathrm{v})$ are 0.59 (Richet et al., 1977) and 0.58 , respectively, but given their similarity to that calculated for $\mathrm{OH}(\mathrm{v})-0.56-$ are not plotted for clarity. The main fractionation in this system is between molecules that do and do not feature the $\mathrm{OH}$ stretching mode. The fractionation factor $(\ln B)$ for atomic hydrogen is zero by definition.

414 These calculations demonstrate that at $3,000 \mathrm{~K}$, the $\mathrm{OH}(\mathrm{v})-\mathrm{H}(\mathrm{v})$ and $\mathrm{OH}(\mathrm{v})-\mathrm{H}_{2}(\mathrm{v})$ isotopic 415 fractionation is approximately 60 and 30 per mil, respectively, while fractionations between $416 \mathrm{H}_{2} \mathrm{O}(\mathrm{v}), \mathrm{OH}(\mathrm{v})$ and $\mathrm{MgOH}(\mathrm{v})$ are relatively minor. Hence, to the extent that $\mathrm{H}_{2}(\mathrm{v})$ and $\mathrm{H}(\mathrm{v})$ 
417 are significant H-bearing species (Figure 2), measurable isotopic fractionation may

418 accompany liquid-vapor equilibration.

419

420 To translate such isotopic calculations into statements about Earth-Moon differences, we

421 must convolve fractionation factors with a physical model that yields relative abundances of

422 the vapor species present as well as the temperatures of liquid-vapor equilibration. For

423 hydrogen isotopic mass balance, we have:

424

${ }_{L}={ }_{\mathrm{OH}}$

425

$$
{ }_{V}=x_{i}{ }_{i}
$$

$$
{ }_{C}=F_{V}^{H}{ }_{V}+\left(1 \quad F_{V}^{H}\right)_{L}
$$

427 where $\delta_{L}, \delta_{V}$, and $\delta_{C}$ represent the isotopic composition of the liquid, vapor, and total

428 column, respectively, $\delta_{i}$ and $x_{i}$ represent the isotopic composition and fraction of vaporized

$429 \mathrm{H}$ atoms in a given species, and $F_{V}^{H}=F_{V}\left(x_{V}^{H} / x^{H}\right)$, expressing the fraction of total

430 hydrogen partitioned into the vapor. Equilibrium isotopic fractionation between a silicate

431 liquid and vapor containing the equilibrium spectrum of species in the proto-lunar disk is 432 displayed in Figure 5. 


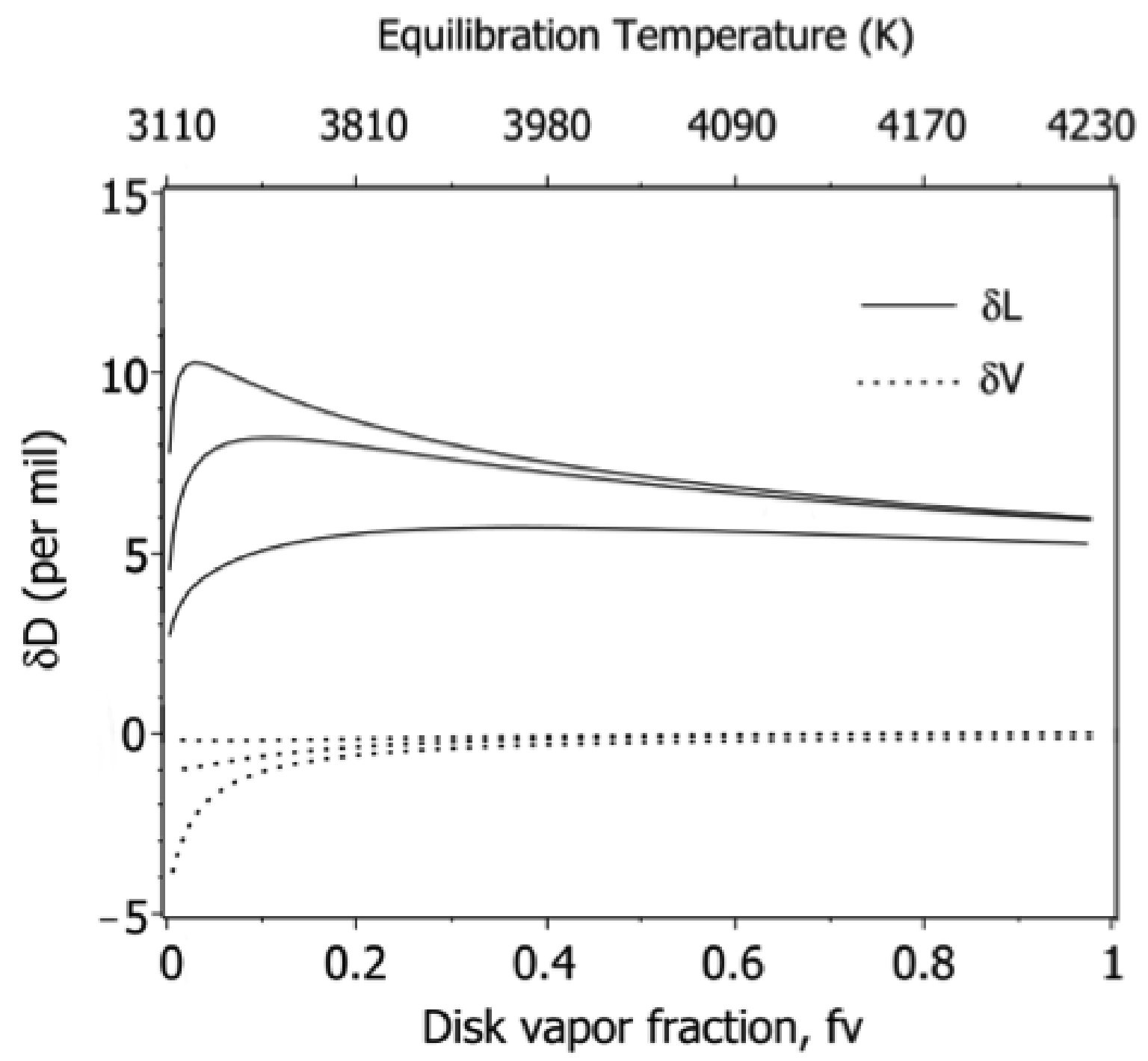

Fig. 5. Equilibrium isotopic fractionation between co-existing reservoirs in the proto-lunar disk. The total column (liquid and vapor) composition is taken to be zero $(\delta=0)$ and the total disk $\left[\mathrm{H}_{2} \mathrm{O}\right]=90,900$, and 9,000 ppm wt for the three illustrated cases. The equilibrium isotopic fractionation for hydrogen in this 2-phase system is 5-10 per mil. An essentially terrestrial $\mathrm{D} / \mathrm{H}$ for lunar $\mathrm{H}$ is consistent with equilibrium dissolution in the proto-lunar disk. The pressure of equilibration is 36 bars at full vaporization $\left(f_{v}=1\right)$ and decreases linearly with decreasing vapor fraction (Equation 6). 
433 Equilibrium $\mathrm{D} / \mathrm{H}$ isotopic fractionation between the proto-lunar liquid and atmosphere,

434 while not negligible, is small $(5-10 \%)$. Hence, a "terrestrial" D/H for lunar water (Barnes et

435 al., 2014; Füri et al., 2014; Saal et al., 2013; Tartèse et al., 2013) is consistent with a

436 terrestrial provenance for the Moon-forming material followed by equilibrium dissolution of

$437 \mathrm{H}$ in the proto-lunar disk. Despite large equilibrium fractionations between individual

438 species ( $\sim 60$ per mil between $\mathrm{OH}(\mathrm{v})-\mathrm{H}(\mathrm{v})$ at 3,000 K), the distinct isotopic compositions of

439 atomic and molecular $\mathrm{H}$ are diluted by the existence of other less isotopically distinct vapor

440 species such as $\mathrm{OH}(\mathrm{v}), \mathrm{MgOH}(\mathrm{v})$ and $\mathrm{H}_{2} \mathrm{O}(\mathrm{v})$. Such calculations are based on the

441 assumption that $\mathrm{OH}(\mathrm{l})$ and $\mathrm{OH}(\mathrm{v})$ are isotopically indistinguishable. A small residual $\mathrm{OH}(\mathrm{l})-$

$442 \mathrm{OH}(\mathrm{v})$ fractionation at these temperatures cannot be excluded, and such a fractionation could

443 shift the results here calculated by, perhaps, several tens of per mil (Dobson et al., 1989;

444 Pineau et al., 1998). Despite this uncertainty, and the difficulty of characterizing the silicate

445 Earth isotopic composition with high precision, one prediction of an equilibrium dissolution

446 origin of lunar hydrogen is that the isotopic composition of juvenile lunar water should be

447 equal to the terrestrial $\mathrm{D} / \mathrm{H}$ value to a precision of tens of per mil.

\section{5. Discussion}

450 5.1. Thermal escape from the Earth-Moon system

451 Here, we have considered liquid-vapor equilibration as a process capable of determining

452 proto-lunar water abundances under the assumption that the post-impact Earth-Moon system

453 behaved as a closed system. How accurate is this assumption? We consider two thermal

454 escape processes: Jeans and hydrodynamic escape. In the case of Jeans escape, the loss is a

455 gas kinetic process with the escaping molecules passing through a low-density exosphere in 
456 which outbound high-velocity molecules have a significant probability of leaving the system

457 without further collision. Defining the exosphere as the location where the mean free path of

458 molecules equals the atmospheric scale height, we derive an exospheric number density of

$459 \sim 10^{7} \mathrm{~cm}^{-3}$. Even assuming that all molecules that impinge on the exosphere escape, the flux

460 of hydrogen that can be eliminated through such a process is limited by the short timescales

461 available $\left(\sim 10^{2}-10^{3}\right.$ years $)$ and is orders of magnitude too low to significantly influence the

462 lunar $\mathrm{H}$ budget. What about hydrodynamic loss in a planetary wind? Hydrodynamic loss

463 from planetary atmospheres is often discussed in relation to the escape parameter $(\lambda)$ defined

464 as the ratio of gravitational potential energy $(G M \mu / r)$ to the thermal energy $(k T)$ of vapor

465 molecules. For large values of the escape parameter (e.g. atomic nitrogen in modern Earth's

466 upper atmosphere), the atmosphere is stable against hydrodynamic escape and adopts instead

467 a hydrostatic state. At sufficiently small values of $\lambda$, escape of a hydrodynamic nature may

468 take place. By adopting $\lambda_{\text {crit }}=3$ (Volkov et al., 2011) and evaluating the escape parameter at

469 the Roche radius $\left(r=3 R_{E}\right)$, the criterion for hydrodynamic escape can be expressed:

$$
S_{S V A}=\frac{}{m_{p}} \div \frac{2000 K}{T} \div<3
$$

471 Hence, at the temperatures relevant to the silicate vapor atmosphere, a hypothetical, pure

472 light gas, e.g. pure $\mathrm{H}(\mathrm{v})$ or $\mathrm{H}_{2}(\mathrm{v})$, would be unstable to with respect to hydrodynamic loss

473 while silicate vapors $\left(\mu=30-40 \mathrm{~m}_{\mathrm{p}}\right)$ are gravitationally bound, stable, and hydrostatic.

474 Moreover, no mechanism is known that can separate the light, unbound, H-bearing species

475 from the heavy silicate vapor molecules efficiently on the relevant timescales in this

476 atmosphere: diffusion-limited gravitational separation - while capable of carrying a small

477 flux of hydrogen across the homopause up to escaping levels - is orders of magnitude too 
478 slow (Nakajima and Stevenson, 2014). Hence, in the presence of gravitationally bound 479 silicate vapors, the $\mathrm{H}$ in the proto-lunar atmosphere is effectively retained via molecular 480 collisions. Toward the end of the thermal history, when silicate vapors have nearly 481 completely condensed, $\mathrm{H}$-speciation at the liquid-vapor interface transitions from $\mathrm{OH}(\mathrm{v})$ $482 \mathrm{H}(\mathrm{v})-\mathrm{MgOH}(\mathrm{v})$ to $\mathrm{H}_{2} \mathrm{O}(\mathrm{v})-\mathrm{H}_{2}(\mathrm{v})$. Whether conditions in such a proto-lunar "steam" 483 atmosphere were conducive to hydrodynamic escape depend on: (1) the H/O ratio of the 484 vapor determined by the redox state of the co-existing magma, (2) the thermal structure of 485 the upper atmosphere and associated speciation equilibria, and (3) the presence or absence of 486 other volatile elements (e.g. C) with high enough abundances to influence the mean 487 molecular weight of the residual vapor. A description of the proto-lunar "steam" atmosphere 488 is beyond the scope of this work - it requires further attention. During the silicate vapor 489 dominated phase of the evolution described here, however, the post-impact Earth-Moon 490 system is essentially closed with respect to $\mathrm{H}$ loss.

491

492 5.2. Fractionation before magma ocean crystallization

493 Here, we have considered liquid-vapor equilibration in the proto-lunar disk, only one 494 process in the post-impact evolution: both crystal-liquid-vapor fractionation during lunar 495 accretion and hydrodynamic escape from a "naked" hydrous magma ocean (Pahlevan and 496 Karato, 2011) are distinct possibilities for $\mathrm{H}$ loss. What assessments can be made about 497 fractionation in these settings? During the lunar accretion process, disk patches with masses $498<10^{-2}$ lunar mass are thought to fragment, generating moonlets that feed lunar accretion 499 (Salmon and Canup, 2012). It is thought that disk fragments form when the disk vapor 500 fraction is sufficiently low $\left(f_{v}<0.01-0.001\right)$ (Thompson and Stevenson, 1988). Given that $f_{v}$ 
$501<0.01$ in our model is attained at super-liquidus temperatures $>3,100 \mathrm{~K}$, we expect the disk

502 fragments to be solid-free upon fragmentation, and accordingly to retain dissolved $\mathrm{H}$

503 (Karato, 2013). Subsequent evolutionary stages may also be considered conducive to

504 volatile loss as the escape parameters for a "naked" magma ocean on the Moon and its

505 preceding moonlets are orders of magnitude lower than that for escape from the Earth-Moon

506 system. Two effects may, nevertheless, hinder fractionation in such settings: first, liquids

507 that fragment to form moonlets have values of entropy such that they co-exist with a silicate

508 vapor at low pressures. Hence, like the silicate vapor atmosphere of the disk, the hydrogen

509 vapors in such settings will be accompanied by silicate vapors, and it is not clear to what

510 extent escape from such moonlets will be selective in nature, a requirement for

511 compositional evolution. Secondly, in the absence of a thick overlying atmosphere, exposed

512 liquids with high radiative fluxes on such bodies might develop rapid quenching and

513 foundering of solid lids, significantly hindering degassing of interior liquids. Moreover, the

$514 \mathrm{~K} / \mathrm{U}$ ratios of lunar reservoirs are uniform, suggesting that the episode of volatile loss had

515 ceased by the onset of lunar magma ocean (LMO) crystallization, otherwise some LMO

516 reservoirs would have recorded a pre-volatile-depletion signature which - at least in the case

517 of potassium - is not observed.

518

519 5.3. Kinetic isotope fractionation

520 We have here only considered equilibrium isotopic fractionation between the liquid and

521 vapor phases. But in this rapidly evolving system - in analogy with terrestrial meteorology -

522 it is possible to imagine departures from equilibrium driving kinetic isotope fractionation

523 with observable consequences. Kinetic isotope fractionation is constrained via potassium 
524 isotopes because of the presently attained precision of the measurements (Humayun and

525 Clayton, 1995), the uniformity of lunar reservoirs with respect to K/U precluding significant

526 degassing of $\mathrm{K}$ during petrogenesis (Prettyman et al., 2006), and near-zero equilibrium

527 isotopic fractionation between an ionically bonded element in the melt and a monatomic

528 vapor (Visscher and Fegley, 2013). The Earth-Moon similarity in K isotopes can therefore

529 be used to set constraints on the maximum departure from equilibrium characterizing liquid-

530 vapor exchange in the post-impact environment (Pritchard and Stevenson, 2000). H

531 isotopes, however, exhibit a distinct, unique behavior that might make them sensitive

532 recorders of kinetics even in scenarios where the isotopes of other elements exhibit no such

533 sensitivity. In silicate melts, the diffusivity of $\mathrm{OH}$ is known to be much less than the

534 diffusivity of molecular $\mathrm{H}_{2} \mathrm{O}$ such that even small equilibrium amounts of $\mathrm{H}_{2} \mathrm{O}$ (or $\mathrm{H}_{2}$ )

535 might dominate the total melt diffusivity of $\mathrm{H}$. The liquid $\mathrm{H}$ abundances here described are

536 sufficiently low such that $\mathrm{OH}$ dominates the liquid speciation over dissolved water or

537 hydrogen molecules. Importantly, as the $\mathrm{H}$ abundance decreases, the melt $\mathrm{OH} / \mathrm{H}_{2} \mathrm{O}$ ratio

538 increases, and the kinetics of diffusion become increasingly slower from melts into bubbles

539 where equilibration with a vapor phase can take place. The ultimate $\mathrm{H}$ abundance of proto-

540 lunar liquids may therefore be determined - not by equilibrium partitioning - but by a

541 progressively decreasing rate of diffusion. While not considered in the equilibrium scenario

542 here described, in such a regime, the kinetics of diffusion for proto-lunar liquids can become

543 the rate-limiting step for hydrogen loss from silicate melts, with significant accompanying

$544 \mathrm{D} / \mathrm{H}$ fractionation. Such effects must be the focus of future studies.

545

546 6. Conclusions 
547 As recently as 2006, lunar interior $\mathrm{H}_{2} \mathrm{O}$ contents were considered to be $<1 \mathrm{ppb}$ (Taylor et

548 al., 2006). In a pioneering study, (Saal et al., 2008) measured indigenous lunar water in

549 volcanic glasses, instigating reevaluations of the bulk lunar $\mathrm{H}$ abundances that currently

550 range from $\leq 1 \mathrm{ppm}$ wt (Albarède et al., 2015) to $\geq 110 \mathrm{ppm}$ wt (Chen et al., 2015). Here,

551 we have investigated whether such recently elevated (ppm-level) inferences of $\mathrm{H}$

552 abundances could have been inherited during the processes accompanying lunar origin. At

553 the Roche radius, where the last equilibration between the proto-lunar disk liquid and vapor

554 may have taken place, the temperatures of equilibration between liquids and vapors can

555 range between $3,100-4,200 \mathrm{~K}$. At these conditions, water vapor undergoes thermal

556 dissociation and reacts with silicate vapor to form an equilibrium spectrum of vapor species,

557 the most abundant of which are hydroxyl $(\mathrm{OH})$, atomic hydrogen $(\mathrm{H})$, and magnesium

558 hydroxide $(\mathrm{MgOH})$ with both water vapor and molecular hydrogen constituting minor $\mathrm{H}$ -

559 bearing species, except when the silicate vapor atmosphere has undergone nearly complete

560 condensation. Such vapor speciation has the influence of decreasing the water fugacity and

561 promoting exsolution from proto-lunar liquids. Nevertheless, we find that - despite

562 extensive degassing into a vapor atmosphere - a small but significant fraction of hydrogen

563 (equivalent to $0.02-0.22$ of the total) is dissolved in proto-lunar liquids that ultimately

564 become the lunar magma ocean. For a range of disk abundances of $\mathrm{H}$ (equivalent to $90-$

5659,000 ppm wt $\mathrm{H}_{2} \mathrm{O}$ ), proto-lunar liquids with $\mathrm{H}_{2} \mathrm{O}$ concentrations broadly consistent with

566 recent, elevated (ppm-level) inferences on lunar water contents (Albarède et al., 2015; Chen

567 et al., 2015) can be obtained. Moreover, recent works have shown that - in the presence of

568 silicate vapor - hydrogen in the proto-lunar disk is gravitationally bound. Together, these

569 results suggest that the lunar inventory of hydrogen may be terrestrial water inherited by the 
570 proto-lunar liquid through equilibrium dissolution. Hence, just as late accretion of

571 comets/asteroids is thought to have made only minor changes to the $\mathrm{H}$ budget of the Earth,

572 late accretion onto the Moon may have been a secondary process as the lunar material may

573 have inherited its water from the Earth and retained it throughout the energetic processes of

574 its formation. The scenario here explored suggests that juvenile lunar "water" should have a

$575 \mathrm{D} / \mathrm{H}$ that is the same as the terrestrial value to within a few tens of per mil. In the future,

576 experimental determination of the solubility of $\mathrm{H}-$ as well as $\mathrm{H}$ isotope fractionation factors

577 - in silicate magmas at the temperatures and compositions of relevance may permit

578 improved forward modeling of the consequences of origins scenarios for lunar hydrogen.

579

580 Acknowledgements: This research was carried out in part through a Bateman Fellowship at 581 Yale University and in part through a Henri Poincaré Fellowship at the Observatoire de la

582 Côte d'Azur (OCA) to K.P. The Henri Poincaré Fellowship is funded by the OCA and the

583 City of Nice. S. K. would like to thank NSF for partial support. B. F. was supported by

584 NASA EPSCOR grant NNX13AE52A. We would like to thank Alessandro Morbidelli for

585 insightful discussions and Francis Albarède and an anonymous reviewer for thorough and 586 helpful reviews.

\section{References}

589 Albarède, F., Albalat, E., Lee, C.T.A., 2015. An intrinsic volatility scale relevant to the Earth and 590 Moon and the status of water in the Moon. Meteoritics \& Planetary Science 50, 568-577.

591 Archer, D., Eby, M., Brovkin, V., Ridgwell, A., Cao, L., Mikolajewicz, U., Caldeira, K., Matsumoto, 592 K., Munhoven, G., Montenegro, A., Tokos, K., 2009. Atmospheric Lifetime of Fossil Fuel Carbon 593 Dioxide. Annual Review of Earth and Planetary Sciences 37, 117-134. 
594

595

596

597

598

599

600

601

602

603

604

605

606

607

608

609

610

611

612

613

614

615

616

617

618

619

620

621

622

623

624

625

626

627

628

629

630

631

632

633

634

635

636

637

Asher, W.E., Karle, L.M., Higgins, B.J., Farley, P.J., Monahan, E.C., Leifer, I.S., 1996. The influence of bubble plumes on air-seawater gas transfer velocities. Journal of Geophysical Research-Oceans 101, 12027-12041.

Barnes, J.J., Tartèse, R., Anand, M., McCubbin, F.M., Franchi, I.A., Starkey, N.A., Russell, S.S., 2014. The origin of water in the primitive Moon as revealed by the lunar highlands samples. Earth and Planetary Science Letters 390, 244-252.

Bottke, W.F., Walker, R.J., Day, J.M.D., Nesvorny, D., Elkins-Tanton, L., 2010. Stochastic Late Accretion to Earth, the Moon, and Mars. Science 330, 1527-1530.

Bunker, P.R., Kolbuszewski, M., Jensen, P., Brumm, M., Anderson, M.A., Barclay, W.L., Ziurys, L.M., Ni, Y., Harris, D.O., 1995. New Rovibrational Data for MgOH and MgOD and the Internuclear Potential Function of the Ground Electronic-State. Chemical Physics Letters 239, 217-222.

Burnham, C.W., Jahns, R.H., 1962. A Method for Determining Solubility of Water in Silicate Melts. American Journal of Science 260, 721-745.

Canup, R.M., 2012. Forming a Moon with an Earth-like Composition via a Giant Impact. Science 338, 1052-1055.

Canup, R.M., Asphaug, E., 2001. Origin of the Moon in a giant impact near the end of the Earth's formation. Nature 412, 708-712.

Canup, R.M., Visscher, C., Salmon, J., Fegley Jr, B., 2015. Lunar volatile depletion due to incomplete accretion within an impact-generated disk. Nature Geosci 8, 918-921.

Chase, M.W., Davies, C.A., Downey, J.R., Frurip, D.J., Mcdonald, R.A., Syverud, A.N., 1985. Janaf

Thermochemical Tables - 3rd Edition .2. Journal of Physical and Chemical Reference Data 14, 927-1856.

Chen, Y., Zhang, Y., Liu, Y., Guan, Y., Eiler, J., Stolper, E.M., 2015. Water, fluorine, and sulfur concentrations in the lunar mantle. Earth and Planetary Science Letters 427, 37-46.

Cuk, M., Stewart, S.T., 2012. Making the Moon from a Fast-Spinning Earth: A Giant Impact

Followed by Resonant Despinning. Science 338, 1047-1052.

Dobson, P.F., Epstein, S., Stolper, E.M., 1989. Hydrogen Isotope Fractionation between

Coexisting Vapor and Silicate-Glasses and Melts at Low-Pressure. Geochimica Et

Cosmochimica Acta 53, 2723-2730.

Fegley, B., Schaefer, L.K., 2014. Chemistry of Earth's Earliest Atmosphere, in: Turekian, H.D.H.K. (Ed.), Treatise on Geochemistry (Second Edition). Elsevier, Oxford, pp. 71-90.

Füri, E., Deloule, E., Gurenko, A., Marty, B., 2014. New evidence for chondritic lunar water from combined D/H and noble gas analyses of single Apollo 17 volcanic glasses. Icarus 229, 109-120.

Hamilton, D.L., Burnham, C.W., Osborn, E.F., 1964. The Solubility of Water and Effects of Oxygen Fugacity and Water Content on Crystallization in Mafic Magmas. Journal of Petrology 5, 21-39.

Hauri, E.H., Saal, A.E., Rutherford, M.J., Van Orman, J.A., 2015. Water in the Moon's interior: Truth and consequences. Earth and Planetary Science Letters 409, 252-264. Hauri, E.H., Weinreich, T., Saal, A.E., Rutherford, M.C., Van Orman, J.A., 2011. High PreEruptive Water Contents Preserved in Lunar Melt Inclusions. Science 333, 213-215. Hirschmann, M.M., 2006. Water, Melting, and the Deep Earth H2O Cycle. Annual Review of Earth and Planetary Sciences 34, 629-653. 
638 Hirschmann, M.M., Withers, A.C., Ardia, P., Foley, N.T., 2012. Solubility of molecular hydrogen

639 in silicate melts and consequences for volatile evolution of terrestrial planets. Earth and

640 Planetary Science Letters 345, 38-48.

641 Hui, H.J., Peslier, A.H., Zhang, Y.X., Neal, C.R., 2013. Water in lunar anorthosites and evidence

642 for a wet early Moon. Nat Geosci 6, 177-180.

643 Humayun, M., Clayton, R.N., 1995. Potassium Isotope Cosmochemistry - Genetic-Implications

644 of Volatile Element Depletion. Geochimica Et Cosmochimica Acta 59, 2131-2148.

645 Jacobson, S.A., Morbidelli, A., Raymond, S.N., O'Brien, D.P., Walsh, K.J., Rubie, D.C., 2014.

646 Highly siderophile elements in Earth's mantle as a clock for the Moon-forming impact. Nature

$647508,84-+$.

648 Karato, S., 2013. Geophysical constraints on the water content of the lunar mantle and its

649 implications for the origin of the Moon. Earth and Planetary Science Letters 384, 144-153.

650 Karsten, J.L., Holloway, J.R., Delaney, J.R., 1982. Ion Micro-Probe Studies of Water in Silicate

651 Melts - Temperature-Dependent Water Diffusion in Obsidian. Earth and Planetary Science

652 Letters 59, 420-428.

653 Khan, A., Connolly, J.A.D., Maclennan, J., Mosegaard, K., 2007. Joint inversion of seismic and

654 gravity data for lunar composition and thermal state. Geophysical Journal International 168,

655 243-258.

656 Koput, J., Carter, S., Peterson, K.A., Theodorakopoulos, G., 2002. The ab initio potential energy

657 surface and vibrational-rotational energy levels of X-2 Sigma(+) MgOH. Journal of Chemical

658 Physics 117, 1529-1535.

659 Kruijer, T.S., Kleine, T., Fischer-Godde, M., Sprung, P., 2015. Lunar tungsten isotopic evidence

660 for the late veneer. Nature 520, 534-537.

661 Larimer, J.W., 1967. Chemical Fractionations in Meteorites - I. Condensation of Elements.

662 Geochimica Et Cosmochimica Acta 31, 1215.

663 Lord, H.C., 1965. Molecular Equilibria and Condensation in a Solar Nebula and Cool Stellar

664 Atmospheres. Icarus 4, 279-\&.

665 Marty, B., 2012. The origins and concentrations of water, carbon, nitrogen and noble gases on

666 Earth. Earth and Planetary Science Letters 313, 56-66.

667 Morbidelli, A., Wood, B.J., 2015. Late Accretion and the Late Veneer, The Early Earth. John

668 Wiley \& Sons, Inc, pp. 71-82.

669 Nagahara, H., Kushiro, I., Mysen, B.O., 1994. Evaporation of Olivine - Low-Pressure Phase-

670 Relations of the Olivine System and Its Implication for the Origin of Chondritic Components

671 in the Solar Nebula. Geochimica Et Cosmochimica Acta 58, 1951-1963.

672 Nakajima, M., Stevenson, D.J., 2014. Hydrodynamic Escape does not Prevent the "Wet" Moon

673 Formation, Lunar and Planetary Science Conference XLV, The Woodlands, Texas.

674 O’Brien, D.P., Walsh, K.J., Morbidelli, A., Raymond, S.N., Mandell, A.M., 2014. Water delivery

675 and giant impacts in the 'Grand Tack' scenario. Icarus 239, 74-84.

676 Pahlevan, K., 2014. Isotopes as tracers of the sources of the lunar material and processes of

677 lunar origin. Philosophical Transactions of the Royal Society a-Mathematical Physical and

678 Engineering Sciences 372.

679 Pahlevan, K., Karato, S., 2011. Volatile loss via outgassing of the lunar magma ocean,

680 Goldschmidt Conference. Mineralogical Magazine, Prague, Czech Republic, p. 1587.

681 Pahlevan, K., Morbidelli, A., 2015. Collisionless encounters and the origin of the lunar

682 inclination. Nature. 
Pahlevan, K., Stevenson, D.J., 2007. Equilibration in the aftermath of the lunar-forming giant impact. Earth and Planetary Science Letters 262, 438-449.

685

686 Pahlevan, K., Stevenson, D.J., Eiler, J.M., 2011. Chemical fractionation in the silicate vapor atmosphere of the Earth. Earth and Planetary Science Letters 301, 433-443. Pineau, F., Shilobreeva, S., Kadik, A., Javoy, M., 1998. Water solubility and D/H fractionation in the system basaltic andesite-H2O at 1250 degrees $\mathrm{C}$ and between 0.5 and 3 kbars. Chemical Geology 147, 173-184.

691

Prettyman, T.H., Hagerty, J.J., Elphic, R.C., Feldman, W.C., Lawrence, D.J., McKinney, G.W., Vaniman, D.T., 2006. Elemental composition of the lunar surface: Analysis of gamma ray spectroscopy data from Lunar Prospector. Journal of Geophysical Research-Planets 111. Pritchard, M.E., Stevenson, D.J., 2000. Thermal aspects of a lunar origin by giant impact, in: Righter, K., Canup, R.M. (Eds.), Origin of the Earth and Moon. University of Arizona Press, Tucson, AZ, pp. 179-196.

Richet, P., Bottinga, Y., Javoy, M., 1977. Review of Hydrogen, Carbon, Nitrogen, Oxygen, Sulfur, and Chlorine Stable Isotope Fractionation among Gaseous Molecules. Annual Review of Earth and Planetary Sciences 5, 65-110.

Rubie, D.C., Jacobson, S.A., Morbidelli, A., O'Brien, D.P., Young, E.D., de Vries, J., Nimmo, F., Palme, H., Frost, D.J., 2015. Accretion and differentiation of the terrestrial planets with implications for the compositions of early-formed Solar System bodies and accretion of water. Icarus 248, 89-108.

Saal, A.E., Hauri, E.H., Lo Cascio, M., Van Orman, J.A., Rutherford, M.C., Cooper, R.F., 2008. Volatile content of lunar volcanic glasses and the presence of water in the Moon's interior. Nature 454, 192-U138.

Saal, A.E., Hauri, E.H., Van Orman, J.A., Rutherford, M.J., 2013. Hydrogen Isotopes in Lunar Volcanic Glasses and Melt Inclusions Reveal a Carbonaceous Chondrite Heritage. Science 340, 1317-1320.

Salmon, J., Canup, R.M., 2012. Lunar Accretion from a Roche-Interior Fluid Disk. Astrophysical Journal 760.

Sharp, Z.D., McCubbin, F.M., Shearer, C.K., 2013. A hydrogen-based oxidation mechanism relevant to planetary formation. Earth and Planetary Science Letters 380, 88-97.

Sharp, Z.D., Shearer, C.K., McKeegan, K.D., Barnes, J.D., Wang, Y.Q., 2010. The Chlorine Isotope Composition of the Moon and Implications for an Anhydrous Mantle. Science 329, 10501053.

Silver, L., Stolper, E., 1985. A Thermodynamic Model for Hydrous Silicate Melts. Journal of Geology 93, 161-177.

Stolper, E., 1982. Water in silicate glasses: an infrared spectroscopic study. Contributions to Mineralogy and Petrology 81, 1-17.

Stolper, E., 1989. Temperature Dependence of the Speciation of Water in Rhyolitic Melts and Glasses. American Mineralogist 74, 1247-1257.

Tartèse, R., Anand, M., Barnes, J.J., Starkey, N.A., Franchi, I.A., Sano, Y., 2013. The abundance, distribution, and isotopic composition of Hydrogen in the Moon as revealed by basaltic lunar samples: Implications for the volatile inventory of the Moon. Geochimica et Cosmochimica Acta 122, 58-74.

Taylor, S.R., Taylor, G.J., Taylor, L.A., 2006. The Moon: A Taylor Perspective. Geochimica Et Cosmochimica Acta 70, 5904-5918. 
728 Thompson, C., Stevenson, D.J., 1988. Gravitational-Instability in 2-Phase Disks and the Origin 729 of the Moon. Astrophysical Journal 333, 452-481.

730 Touboul, M., Puchtel, I.S., Walker, R.J., 2015. Tungsten isotopic evidence for disproportional

731 late accretion to the Earth and Moon. Nature 520, 530-533.

732 Urey, H.C., 1947. The Thermodynamic Properties of Isotopic Substances. Journal of the 733 Chemical Society, 562-581.

734 Visscher, C., Fegley, B., 2013. Chemistry of Impact-Generated Silicate Melt-Vapor Debris 735 Disks. Astrophysical Journal Letters 767.

736 Volkov, A.N., Johnson, R.E., Tucker, O.J., Erwin, J.T., 2011. Thermally Driven Atmospheric

737 Escape: Transition from Hydrodynamic to Jeans Escape. Astrophysical Journal Letters 729.

738 Ward, W.R., 2012. On the Vertical Structure of the Protolunar Disk. Astrophysical Journal

739744.

740 Warren, P.H., 2005. "New" lunar meteorites: Implications for composition of the global lunar

741 surface, lunar crust, and the bulk Moon. Meteoritics \& Planetary Science 40, 477-506.

742 Yamashita, S., 1999. Experimental study of the effect of temperature on water solubility in

743 natural rhyolite melt to $100 \mathrm{MPa}$. Journal of Petrology 40, 1497-1507.

744 Young, E.D., Kohl, I.E., Warren, P.H., Rubie, D.C., Jacobson, S.A., Morbidelli, A., 2016. Oxygen

745 isotopic evidence for vigorous mixing during the Moon-forming giant impact. Science 351,

746 493-496.

747 Zahnle, K.J., Kasting, J.F., Pollack, J.B., 1988. Evolution of a Steam Atmosphere during Earth's

748 Accretion. Icarus 74, 62-97. 